\title{
When Anxiety and Depression Coexist: The Role of Differential Diagnosis Using Clinimetric Criteria
}

\author{
Fiammetta Cosci $\mathrm{i}^{\mathrm{a}, \mathrm{b}}$ Giovanni A. Fava ${ }^{\mathrm{c}}$ \\ ${ }^{a}$ Department of Health Sciences, University of Florence, Florence, Italy; ${ }^{b}$ Department of Psychiatry and \\ Neuropsychology, Maastricht University, Maastricht, The Netherlands; ' ${ }^{\circ}$ Department of Psychiatry, University at \\ Buffalo, State University of New York, New York, NY, USA
}

\section{Keywords}

Depression · Anxiety · Psychotropic drugs · Cognitive behavioral therapy · Clinimetrics - Medicine-based evidence · Well-being therapy

\begin{abstract}
Depressive and anxiety disorders are frequently associated. Depression may be a complication of anxiety and anxiety can complicate depression. The nature of their relationship has been a source of controversy. Reviews generally base their conclusions on randomized controlled trials and metaanalyses that refer to the average patient and often clash with the variety of clinical presentations that may occur when anxiety and depression coexist. The aim of this review was to examine the literature according to profiling of subgroups of patients based on clinimetric criteria, in line with the recently developed concept of medicine-based evidence. We critically reviewed the literature pertaining to the specific presentations of anxiety and depression, outlining the advantages and disadvantages of each treatment approach. The following prototypic cases were presented: depression secondary to an active anxiety disorder, depression in patients with anxiety disorders under treatment, anxious
\end{abstract}

depression, anxiety as a residual component of depression, and demoralization secondary to anxiety disorder. We argue that the selection of treatment when anxiety and depression coexist should take into account the modalities of presentation and be filtered by clinical judgment. Very different indications may ensue when the literature is examined according to this perspective.

(c) 2021 S. Karger AG, Basel

\section{Introduction}

Major depressive disorder and anxiety disorder commonly coexist [1-4], being present in up to $25 \%$ of general practice patients [5] and in $80 \%$ of drug-naïve patients [6]. Their close relationship has been a long-standing clinical observation. Depression is a frequent complication of anxiety disorders $[7,8]$ and, vice versa, anxiety is a common complication of depression [3, 9-11].

The nature of the relationship between anxiety and depression has been a source of controversy $[3,8,9,12-15]$. Current clinical practice is to diagnose both disorders separately and refer to comorbidity [16]. A clear-cut op- 
timal treatment strategy for co-occurring anxiety and depression is still lacking and a trans-diagnostic approach is advocated [16]. However, following the evidence-based medicine (EBM) model, reviews and guidelines refer their findings to the "average" patient and apply customary clinical taxonomy based on DSM-5 [17]. Diagnostic criteria do not include patterns of symptoms, severity of illness, effects of comorbid conditions, timing of phenomena, rate of progression of illness, responses to previous treatments, and other clinical distinctions that demarcate major prognostic and therapeutic differences among patients who otherwise seem to be deceptively similar since they share the same psychiatric diagnosis [18]. Such assessment is subsumed under the rubric of clinimetrics, the science of clinical measurements [1820].

There is no simple "average" solution to most medical problems. The question is how to put the available evidence within the context of individual, unique assets and liabilities. There is thus the need of integrating the information that derives from EBM with medicine-based evidence (MBE) [21]. MBE attempts to produce fine-grained profiling of subgroups of patients based on clinimetric criteria. The aim of this review was to provide such profiling in the setting of anxiety associated with depression.

\section{Methods}

A computerized search was carried out (from PubMed inception to March 2021) using as key words: "anxiety AND depression." In addition, the reference lists from existing reviews and from the articles retrieved were inspected. Only English language articles that were published in peer-reviewed journals were included. The prototype diagnostic configuration of disorders [21] was used as the method of dissecting the most frequent clinical presentations of anxiety and depression in adults. It allows the clinician to compare a patient's overall clinical presentation to a set of diagnostic prototypes and rate the extent of match of the patient's clinical presentation to the prototype [22]. Assessment of comorbidity was based on clinimetric principles as any "additional co-existing ailment" separate from the primary disease, even in cases where this secondary phenomenon does not qualify as a disease per se [23]. Comorbidity included the unfavorable modifications in the course, characteristics, and responsiveness to treatment of an illness that may be related to previously administered therapies, i.e., iatrogenic comorbidity [24].

The comorbidity profile that ensued was submitted to macroanalysis, a method developed for organizing clinical data as variables in clinical reasoning $[18,25]$. Macro-analysis starts from the assumption that in most cases there are functional relationships with other more or less clearly defined problem areas and that the targets of treatment may vary during the course of disturbances $[18,25]$. It was thus applied to establish a relationship between cooccurring ailments and to establish what to treat first, also taking into account the primary/secondary distinction [26]. For instance, after months of panic disorder, an individual may become depressed; in this case depression is defined as secondary. Vice versa, if a patient develops a depressive disorder that, after a few months, becomes characterized by panic attacks, depression in this case is defined as primary. The staging method $[27,28]$ allowed us to analyze the longitudinal interplay between anxiety and depression, viewed as two symptomatic stages of the same affective disorder, with the ratio that assessment and treatment depend on when the observation is made [29]. Advantages and disadvantages of therapeutic approaches in the specific prototype setting were outlined, with particular reference to potential benefits, likelihood of responsiveness to the treatment option, and vulnerability to the adverse effects of treatment [30].

\section{From Research to Clinical Practice}

The following interactions between mood disorders and anxiety disturbances were selected.

\section{A. Depression Secondary to an Active Anxiety \\ Disorder}

The occurrence of a major depressive disorder after the onset of an anxiety disorder is common $[31,32]$. Noyes et al. [32] observed brief depressive episodes in $44 \%$ of patients with anxiety disorders over 6 years. Such episodes do not necessarily require specific treatment and may improve with appropriate therapy of the underlying anxiety disturbance. It is thus important to determine the type of intervention that is requested, as the clinical case illustrates.

\section{Clinical Presentation}

Julia is a 50 -year-old housewife with a long-standing history of hypochondriacal fears and somatic symptoms. She always considered them as part of the way she was. In the last 5 years, after her mother's death, she also suffered from agoraphobia with panic attacks, which she tried to manage by relying on her husband accompanying her to places. A few months after the onset of panic attacks and agoraphobia, she developed irritability, difficulties concentrating, low mood, and loss of appetite, which were followed by lack of energy and motivation. Only then did she ask for treatment.

\section{Assessment and Diagnosis}

Macroanalysis. The patient fulfilled the criteria for a major depressive episode, panic disorder, and agoraphobia. Depression occurred after the onset of panic disorder. She still had hypochondriacal fears and somatic symptoms and started having problems with her husband 
Fig. 1. Macroanalysis of Julia's clinical case.

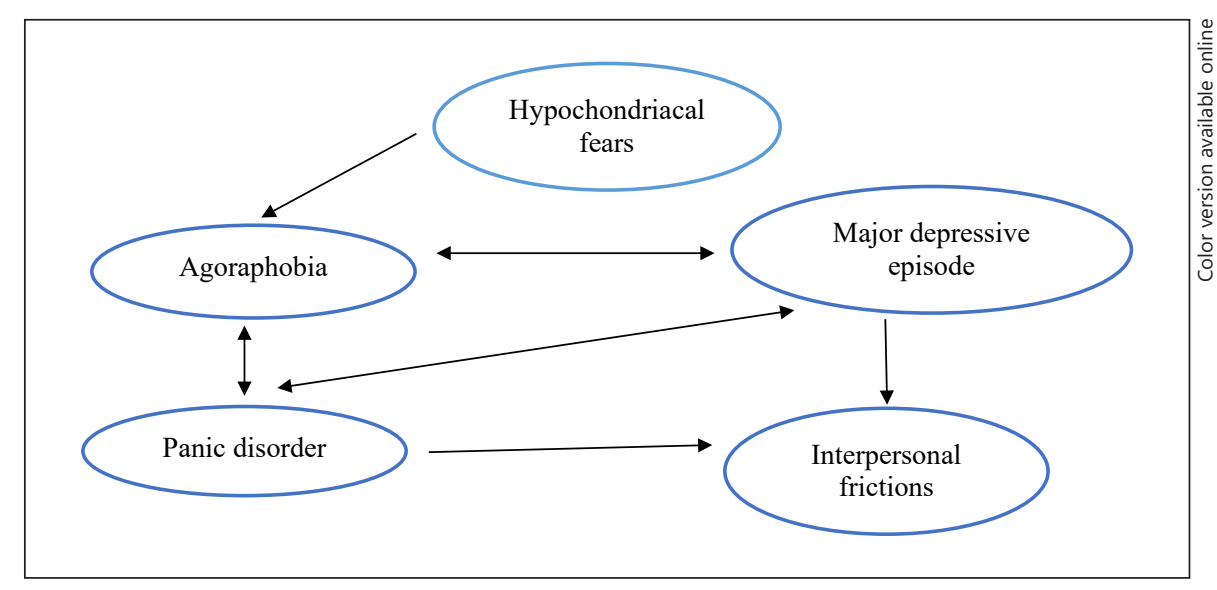

since she needed to be accompanied very often (shown in Fig. 1).

Staging. In accordance with the view of panic disorder as a stage of development of previous anxiety and mood disturbances [27], Julia was on stage 3 (online suppl. Table S1; see www.karger.com/doi/10.1159/000517518 for all online suppl. material).

\section{Treatment Options}

Cognitive behavioral treatment (CBT) of panic disorder and agoraphobia may be efficacious regardless of the baseline depression level [33]. Therefore, one option would be that of treating this patient with CBT only, with the clinical advantage of not having drug treatment, which may negatively interfere with psychotherapy regarding the long-term outcome [34]. However, patient preferences should be addressed, and she was asking for rapid control of symptomatology. In addition, the rapidity of symptom onset may herald further deterioration [27] and the impaired energy and motivation levels may hinder exposure homework, which is necessary for overcoming agoraphobic fears. The other option would be that of endorsing a sequential combination of treatment, using an antidepressant first and adding CBT when remission from depression occurs, with subsequent tapering and discontinuation of the antidepressant [35]. In the case of mild depression, another option would be a sequential combination of treatments which includes a benzodiazepine [36] first and CBT when improvement from panic attacks occurs, with subsequent tapering and discontinuation of the benzodiazepine. In the case of this patient the first sequential model was used [35], with tapering and discontinuation of the antidepressant medication. Since the patient did not reach a full recovery after
CBT, well-being therapy (WBT) [37, 38], a short-term psychotherapeutic strategy that pursues self-observation of instances of well-being, was added [39]. The sequential combination was effective in abating symptoms of agoraphobia, depression, and panic. Interpersonal frictions faded away after WBT.

\section{B. Depression in Patients with Anxiety Disorders Under Treatment}

If the patient with an anxiety disorder is under treatment (particularly if antidepressant drugs are used), the potential iatrogenic role of therapy needs to be evaluated [40]. Demoralization and mood disturbances may occur during treatment of agoraphobia and panic with CBT [41]. Depression may also ensue during antidepressant treatment [42]. The overall situation may be complicated, as this case illustrates.

\section{Clinical Presentation}

Thomas is a 35-year-old, single, white-collar worker. He has been taking citalopram for social anxiety for 2 years (20 mg at bedtime) and reported a mild improvement in anxiety. Citalopram had been prescribed by the family doctor. Recently, however, he started feeling sad, had late insomnia, loss of interest in life, and reported a decrease in appetite and energy. His anxiety considerably increased, especially when he tried to approach women, and a panic attack occurred. The family doctor increased citalopram to $40 \mathrm{mg}$ per day with no results.

\section{Assessment and Diagnosis}

Macroanalysis. The patient met DSM-5 criteria for a major depressive episode and social anxiety disorder. $\mathrm{He}$ also reported one isolated panic attack. The loss of clinical 
Fig. 2. Macroanalysis of Thomas' clinical

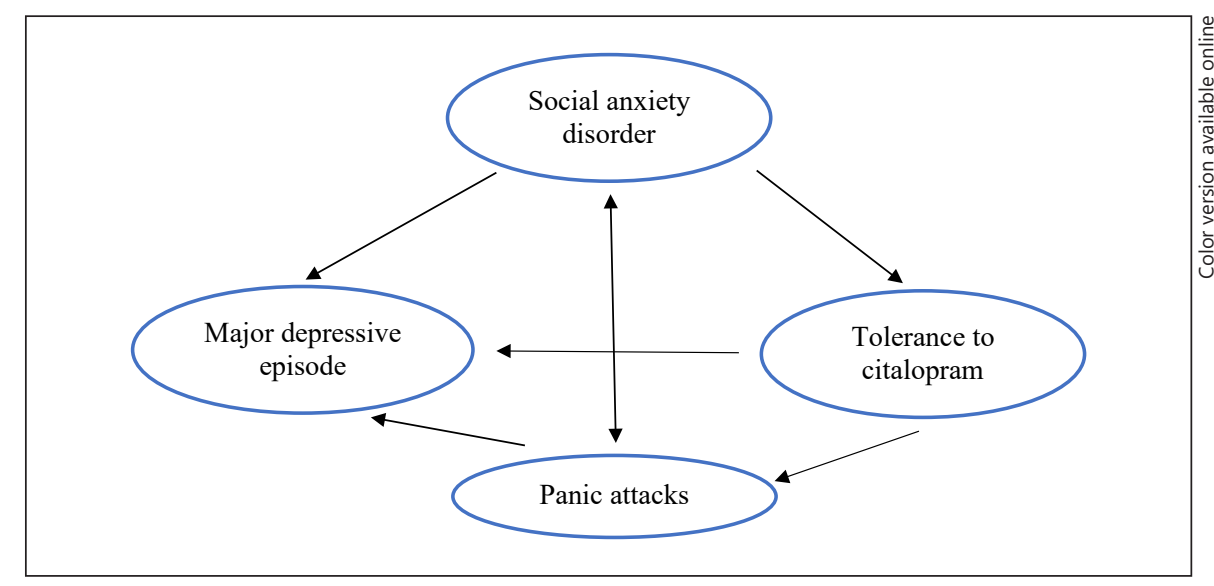
case.

effect after 2 years of treatment with citalopram, as well as the refractoriness to dose increase, are well documented in the literature $[40,43]$. The patient de facto did not respond to the first course of treatment. Thomas's macroanalysis is illustrated in Figure 2.

Staging. In accordance with the view of panic disorder as a stage of development of previous anxiety and mood disturbances [27], Thomas was moving from stage 2 to stage 3 .

\section{Treatment Options}

Fux et al. [42] observed depressive symptoms in 7 out of 80 patients during the treatment of panic disorder with fluvoxamine. The symptoms abated when fluvoxamine was discontinued, and tricyclic antidepressants or clonazepam were prescribed; symptoms reappeared when fluoxetine was introduced. Similar findings were reported during the follow-up of patients receiving tricyclic antidepressants for panic disorder [44]. Furthermore, a relationship between the use of antidepressants and increased relapse risk of panic disorder was observed [45-47].

In the long-term treatment of depression, when loss of clinical effect occurs, an increase in dosage is unlikely to yield lasting remission [48], as was found to be the case with this patient. Thus, in this case, citalopram was tapered and discontinued, with the help of clonazepam [49] since withdrawal symptoms occurred despite tapering [34]. Augmenting strategies or switching to another antidepressant were not chosen, because of the potential occurrence of further behavioral toxicity [43]. In Thomas's case, his mood improved but social anxiety persisted despite use of clonazepam. CBT was thus added to the treatment and yielded an improvement; clonazepam was tapered and discontinued.

When Anxiety and Depression Coexist

\section{Anxious Depression}

About half of outpatients with major depressive disorder have clinically meaningful levels of anxiety [50-52]. Such characterization must be differentiated from mixed anxiety-depressive disorder, that is subsyndromal symptoms of major depression, generalized anxiety disorder, or any other full-syndrome disorder [53]. Rickels et al. [54] observed that outpatients classified on relative degrees of depression and anxiety differed in their response to amitriptyline, chlordiazepoxide, their combination, or placebo. However, the response of patients with low levels of depression and anxiety did not differentiate active treatment and placebo [54]. The clinical case illustrates the difficulties entailed by the concept of anxious depression.

\section{Clinical Presentation}

Mary is a 46-year-old, divorced, blue collar worker who presented with high anxiety, hypochondriacal fears, worry, depressed mood, irritability, sleep difficulties, lack of appetite and energy, and sense of guilt. A few weeks earlier the man she was engaged to for many years abandoned her and the patient became single. She started to be extremely worried about not finding another life companion because of her age. Her family doctor prescribed sertraline $50 \mathrm{mg}$ at bedtime with little success. It was also discontinued because of side effects such as nausea and diarrhea.

\section{Assessment and Diagnosis}

Macroanalysis. The patient met DSM-5 criteria for a major depressive episode. Her disturbances did not reach the threshold for anxiety disorder, even though she appeared to be very anxious, tense, and worried. At a more careful examination, depressive symptoms had modest 
Fig. 3. Macroanalysis of Mary's clinical

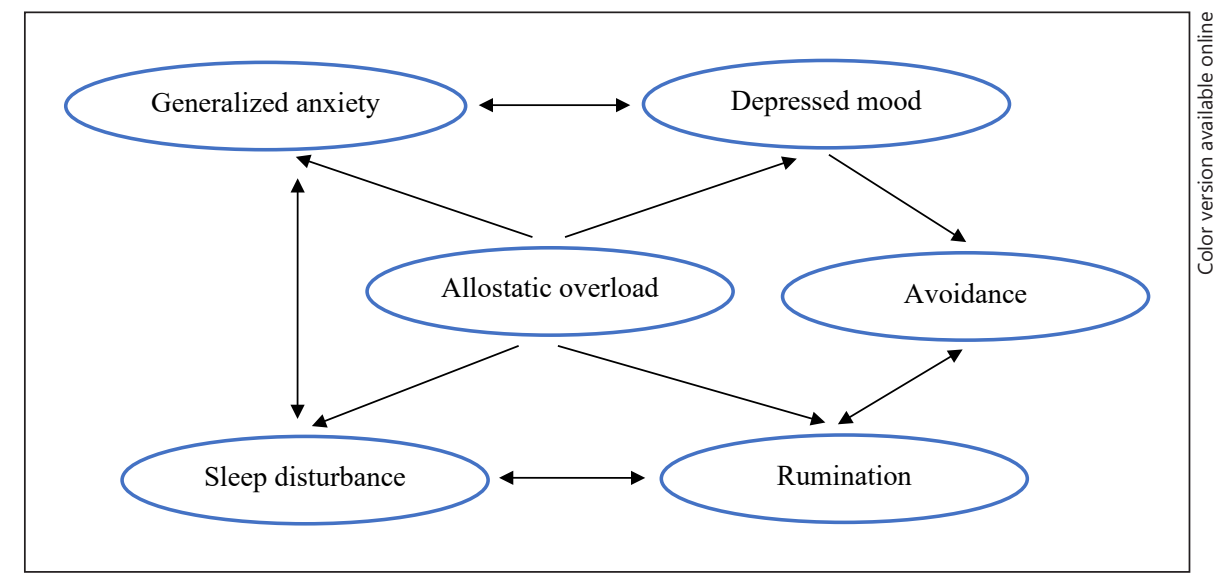

intensity and fluctuated, which is more characteristics of cyclothymic than unipolar depression. Furthermore, the patient appeared to be under considerable stress which exceeded her coping skills (i.e., allostatic overload) [55] and spent most of the time at home chatting with family members or friends on her mobile. Mary's macroanalysis is illustrated in Figure 3.

Staging. Based on the staging model of unipolar depression [27] (online suppl. Table S2), the patient was at stage 2 .

\section{Treatment Options}

The patient had already been treated with an antidepressant with little success. One could, of course, change antidepressant, but the chances of a response would be low [50-54]. Low-dose temporary use of a benzodiazepine (e.g., clonazepam $0.5 \mathrm{mg}$ twice per day) may attenuate the patient's symptoms, but it is not likely to address the depressive symptomatology. One may also give priority to anxiety disturbances (despite being subthreshold) and address them as a primary target of a CBT treatment. This was the approach used in Mary's case. CBT included suggesting lifestyle modification (e.g., stop chatting on mobile, maintain a scheme of daily life activities, actively pursuing social activities). The patient progressively recovered, regaining possession of her own daily life and depressive symptoms faded over time.

\section{Anxiety as a Residual Component of Depression}

Anxiety disturbances may characterize the residual phase of major depression (stage 3 in online suppl. Table S2) [27], which favor residual disability $[56,57]$ and increase the risk of relapse, up to $60 \%$ after 5 years $[58,59]$, as the following case illustrates.

\section{Clinical Presentation}

Mark is a 43-year-old building contractor, married with no children. He had a major depressive episode 3 years earlier, which was treated by the family doctor with fluoxetine for 4 months. After the end of this first depressive episode, moderate fear of having another depressive episode or health problems and mild agoraphobia persisted as residual symptoms. Mark recently had a diagnosis of spondylarthrosis which immediately triggered one isolated panic attack, followed by severe fear and worry for his health. A few weeks later, a second major depressive episode occurred. He wanted to know which treatment was right for him at that point.

\section{Assessment and Diagnosis}

Macroanalysis. The patient satisfied the DSM-5 criteria for major depressive illness, but careful evaluation disclosed hypochondriacal fears, worry for health, and marital crisis (as a result of a busy working life which created a distance with his spouse). In the macroanalysis (Fig 4a), the clinician could give priority to pharmacotherapy of major depressive disorder, leaving the other components to post-therapy assessment (i.e., hypochondriacal fears, worry for health, and the relationship between working life and marital crisis). If the clinical decision of tackling one syndrome may be taken during the initial assessment, the subsequent steps of macroanalysis require a reassessment after the first line of treatment has terminated (shown in Fig. 4b).

Staging. Based on the staging model of unipolar depression [27] (online suppl. Table S2), the patient was first at stage 3 and went back to stage 2 after the diagnosis of spondylarthrosis. 


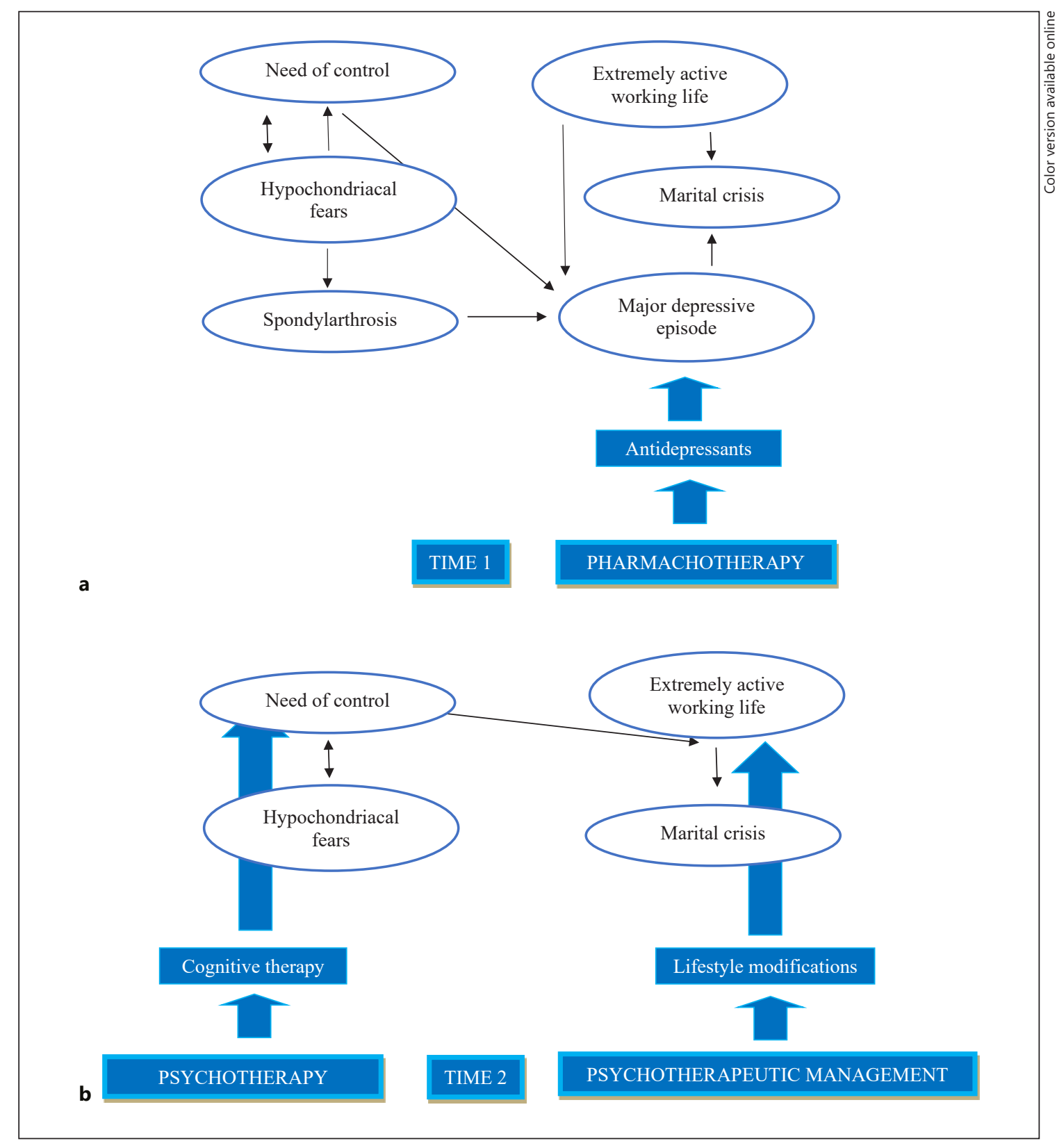

Fig. 4. Macroanalysis of Mark's clinical case before (a) and after (b) first-line treatment.

\section{Treatment Options}

A sequential strategy based on the use of pharmacotherapy in the acute phase of depression and a psychotherapeutic approach in its residual phase has been developed [60] (online suppl. Table S3) and was found to be a viable strategy for preventing relapse in major depressive disorder in a number of randomized controlled trials [35]. In this model, psychotherapy addresses problems and symptoms that were unaffected by the drug treatment and is often different from first-line approaches (e.g., WBT, mindfulness-based cognitive therapy) [35]. An alternative option would be to provide additional pharmacotherapeutic strategies that may address symptoms such as worry and fears. A potential disadvantage in the latter case is the risk of activating clinical manifestations of behavioral toxicity, which might include extend- 


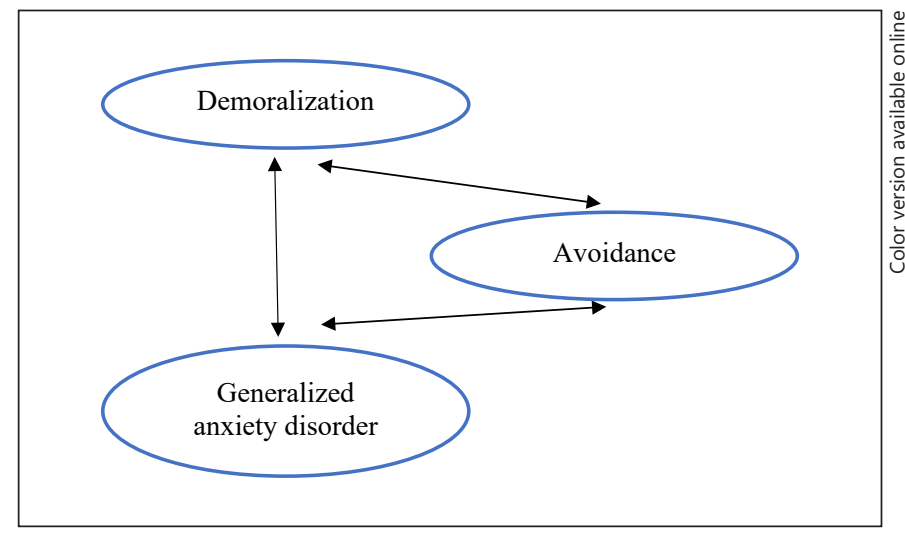

Fig. 5. Macroanalysis of Liza's clinical case.

ed withdrawal phenomena, resistance to the same treatment, and increased vulnerability to relapse [40].

Sequential treatment, that is drug treatment of the acute episode of depression followed by psychotherapy in the residual phase [61], was applied to Mark's case. Fluoxetine was reintroduced at time 1; as soon as the acute symptoms remitted a second macro-analysis was run and, at time 2, the therapist used cognitive restructuring to intervene on residual symptoms (i.e., hypochondriacal fears, need for control). The daily working life that led to communicative difficulties with his partner was approached by proposing lifestyle modifications in the setting of WBT $[37,38]$. The patient was in full remission and drug free at a follow-up of 3 years.

\section{E. Demoralization Secondary to Anxiety Disorder}

Demoralization is a feeling state characterized by a patient's perception of impotence and inability to deal/cope with pressing problems and receive adequate support from others [55]. A feeling of having failed to meet their own or other expectations and lack of hope that problems will be solved are also present [55]. It can be encountered with anxiety disorders $[62,63]$, particularly in agoraphobia and panic [64]. It can be associated with major depression or occur independently, as in the case here illustrated.

\section{Clinical Presentation}

Liza is a 45 -year-old, single, architect. She has suffered from generalized anxiety since she was 20 years old; the family doctor managed anxiety by prescribing alprazolam $0.25 \mathrm{mg}$, when needed. In the last 2 months, she perceived to be unable to cope with pressing problems at work, when she had tight deadlines and inadequate support from others. In addition, she had the feeling of having failed to meet her own expectations (e.g., having a family, having children) and believed there were no solutions for these problems and difficulties.

\section{Assessment and Diagnosis}

Macroanalysis. The patient satisfied DSM-5 criteria for generalized anxiety disorder; she also suffered from demoralization, according to the Diagnostic Criteria for Psychosomatic Research [55] (shown in Fig. 5). Due to demoralization, Liza tended to avoid social situations and spent her spare time on the sofa taking naps or watching $\mathrm{TV}$, although she felt highly dissatisfied by her lifestyle.

\section{Treatment Options}

Demoralization is frequently subsumed under the rubric of minor depression. However, demoralization has specific features [55], which allow its differentiation from major depression, minor depression, and adjustment disorder.

It is conceivable, even though yet to be tested, that demoralization occurring during CBT may improve during the continuation of therapy [33] or respond to specific cognitive strategies, whereas depressive features may require pharmacological treatment. Unfortunately, there has been insufficient research on the characteristics of demoralization in the setting of anxiety disorders [64] and its response to psychotherapy $[65,66]$. A recent randomized controlled trial on the treatment of demoralization and depression in acute coronary syndrome [67] indicated the efficacy of the sequential combination of CBT and WBT.

Liza was engaged in cognitive and behavioral strategies which resulted in a partial remission of her symptoms.

\section{Conclusion}

Reviews generally base their conclusions on randomized controlled trials and meta-analyses (e.g., Saha et al. [68]) that refer to the average patient [69] and may thus clash with the variety of clinical presentations. Very different, if not diverging, indications may ensue when the literature is examined based on the modalities of clinical presentations and when therapeutic options are evaluated in light of potential benefits, likelihood of responsiveness, and vulnerability to adverse events.

There is no simple "average" solution to most psychiatric problems, such as comorbid anxiety and depression, 
and the solution is not represented by overdiagnosing [70]. The question is how to put the available evidence within the context of individual, unique assets and liabilities. There is thus the need for integrating the information that derives from EBM with MBE [21]. A clinimetric approach that includes repeated assessments, macroanalysis, staging, broadening of clinical information, and consideration of iatrogenic comorbidity [20,27, 43] appears to be necessary when anxiety and depression coexist. Similar considerations may be extended to depression with psychotic features [71] or in the setting of psychotic disorders [72].

Such an approach calls for a renaissance of psychopathology (observation, interviewing, classification and differential diagnosis of signs and symptoms) as the basic neglected method of clinical psychiatry, which may lead to an overdue critical scrutiny of current conceptual models that clash with clinical reality. It might also override the limits of the existing guidelines in the literature, with recommendations referring to a hypothetic "average" patient, shedding some light on "real" patients in naturalistic settings. This approach also seems syntonic with the perspective of a dimensional psychopathology, which is in need of been integrated into the diagnostic process [73].
Psychiatrists, who in their clinical practice use sophisticated forms of clinical judgment and master techniques of interviewing and history taking, are ready to reveille something that has not vanished, but that is simply buried under inadequate conceptual models.

\section{Statement of Ethics}

Original data were not collected, thus ethical committee approval was not needed.

\section{Conflict of Interest Statement}

The authors have no conflicts of interest to declare.

\section{Funding Sources}

There are no funding sources to declare.

\section{Author Contributions}

The authors contributed equally.

\section{References}

1 Fava GA, Tomba E. Treatment of comorbid anxiety disorders and depression. In: Emmelkamp P, Ehring T, editors. The Wiley Handbook of Anxiety Disorders. Chichester: Wiley-Blackwell; 2014. pp. 1165-82.

2 Hasin DS, Sarvet AL, Meyers JL, Saha TD, Ruan WJ, Stohl M, et al. Epidemiology of adult DSM-5 major depressive disorder and its specifiers in the United States. JAMA Psychiatry. 2018 Apr;75(4):336-46.

3 Mathew AR, Pettit JW, Lewinsohn PM, Seeley JR, Roberts RE. Co-morbidity between major depressive disorder and anxiety disorders: shared etiology or direct causation? Psychol Med. 2011 Oct;41(10):2023-34.

4 Zimmerman M, Chelminski I, McDermut W. Major depressive disorder and axis I diagnostic comorbidity. J Clin Psychiatry. 2002 Mar;63(3):187-93.

5 Tiller JW. Depression and anxiety. Med J Aust. 2013 Sep;199 S6:S28-31.

6 Yang W, Zhang G, Jia Q, Qian ZK, Yin G, Zhu $\mathrm{X}$, et al. Prevalence and clinical profiles of comorbid anxiety in first episode and drug naïve patients with major depressive disorder. J Affect Disord. 2019 Oct;257:200-6.

7 Marks IM. Fears, phobias and rituals. New York: Oxford University Press; 1987.
8 Meier SM, Petersen L, Mattheisen M, Mors O, Mortensen PB, Laursen TM. Secondary depression in severe anxiety disorders: a population-based cohort study in Denmark. Lancet Psychiatry. 2015 Jun;2(6):515-23.

9 Ranøyen I, Lydersen S, Larose TL, Weidle B, Skokauskas N, Thomsen PH, et al. Developmental course of anxiety and depression from adolescence to young adulthood in a prospective Norwegian clinical cohort. Eur Child Adolesc Psychiatry. 2018 Nov;27(11):1413-23.

10 Lallukka T, Mekuria GB, Nummi T, Virtanen $\mathrm{P}$, Virtanen M, Hammarström A. Co-occurrence of depressive, anxiety, and somatic symptoms: trajectories from adolescence to midlife using group-based joint trajectory analysis.BMCPsychiatry.2019Aug;19(1):236.

11 Merikangas KR, Zhang H, Avenevoli S, Acharyya S, Neuenschwander M, Angst J; Zurich Cohort Study. Longitudinal trajectories of depression and anxiety in a prospective community study: the Zurich Cohort Study. Arch Gen Psychiatry. 2003 Oct;60(10):993-1000.

12 Borsboom D. Psychometric perspectives on diagnostic systems. J Clin Psychol. 2008 Sep;64(9):1089-108.
13 Blanco C, Rubio J, Wall M, Wang S, Jiu CJ, Kendler KS. Risk factors for anxiety disorders: common and specific effects in a national sample. Depress Anxiety. 2014Sep;31(9):75664.

14 Taporoski TP, Negrão AB, Horimoto AR, Duarte NE, Alvim RO, de Oliveira CM, et al. Shared genetic factors of anxiety and depression symptoms in a Brazilian family-based cohort, the Baependi Heart Study. PLoS One. 2015 Dec;10(12):e0144255.

15 Waszczuk MA, Zavos HM, Gregory AM, Eley TC. The phenotypic and genetic structure of depression and anxiety disorder symptoms in childhood, adolescence, and young adulthood. JAMA Psychiatry. 2014 Aug;71(8):90516.

16 Spijker J, Muntingh A, Batelaan N. Advice for clinicians on how to treat comorbid anxiety and depression. JAMA Psychiatry. 2020 Jun;77(6):645-6.

17 American Psychiatric Association. Diagnostic and statistical manual of mental disorders - DSM-5. 5th ed. Arlington: American Psychiatric Publishing; 2013.

18 Fava GA, Rafanelli C, Tomba E. The clinical process in psychiatry: a clinimetric approach. J Clin Psychiatry. 2012 Feb;73(2):177-84. 
19 Feinstein AR. Clinimetrics. London: Yale University Press; 1987. https://doi. org/10.2307/j.ctt1xp3vbc.

20 Fava GA, Tomba E, Sonino N. Clinimetrics: the science of clinical measurements. Int $J$ Clin Pract. 2012 Jan;66(1):11-5.

21 Lobitz G, Armstrong K, Concato J, Singer BH, Horwitz RI. The biological and biographical basis of precision medicine. Psychother Psychosom. 2019;88(6):333-40.

22 Westen D. Prototype diagnosis of psychiatric syndromes. World Psychiatry. 2012 Feb;11(1):16-21.

23 Feinstein AR. The pre-therapeutic classification of comorbidity in chronic disease. J Chronic Dis. 1970 Dec;23(7):455-68.

24 Fava GA, Cosci F, Offidani E, Guidi J. Behavioral toxicity revisited: iatrogenic comorbidity in psychiatric evaluation and treatment. $J$ Clin Psychopharmacol. 2016 Dec;36(6):5503.

25 Emmelkamp PM, Bouman TK, Scholing A. Anxiety disorders. Chichester: Wiley; 1993. pp. 55-67.

26 Robins E, Guze SB. Classification of affective disorders: the primary-secondary, the endogenous-reactive, and the neurotic-psychotic concepts. In: Williams TA, Katz MM, Shield JA, editors. Recent advances in the psychobiology of the depressive illness. Washington: Government Printing Office; 1972. pp. 28393.

27 Cosci F, Fava GA. Staging of mental disorders: systematic review. Psychother Psychosom. 2013;82(1):20-34.

28 Fava GA, Kellner R. Staging: a neglected dimension in psychiatric classification. Acta Psychiatr Scand. 1993 Apr;87(4):225-30.

29 Roth M, Mountjoy CQ. The distinction between anxiety states and depressive disorders. In: Paykel ES, editor. Handbook of Affective Disorders. New York: Guilford Press; 1982. pp. 70-92.

30 Richardson WS, Doster LM. Comorbidity and multimorbidity need to be placed in the context of a framework of risk, responsiveness, and vulnerability. J Clin Epidemiol. 2014 Mar;67(3):244-6.

31 Fava M, Rankin MA, Wright EC, Alpert JE, Nierenberg AA, Pava J, et al. Anxiety disorders in major depression. Compr Psychiatry. 2000 Mar-Apr;41(2):97-102.

32 Noyes R Jr, Clancy J, Hoenk PR, Slymen DJ. The prognosis of anxiety neurosis. Arch Gen Psychiatry. 1980 Feb;37(2):173-8.

33 Emmrich A, Beesdo-Baum K, Gloster AT, Knappe S, Höfler M, Arolt V, et al. Depression does not affect the treatment outcome of CBT for panic and agoraphobia: results from a multicenter randomized trial. Psychother Psychosom. 2012;81(3):161-72.

34 Cosci F, Chouinard G. Acute and persistent withdrawal syndromes following discontinuation of psychotropic medications. Psychother Psychosom. 2020;89(5):283-306.
35 Guidi J, Fava GA. Sequential combination of pharmacotherapy and psychotherapy in major depressive disorder: a systematic review and meta-analysis. JAMA Psychiatry. 2021 Mar;78(3):261-9.

36 Benasi G, Guidi J, Offidani E, Balon R, Rickels $\mathrm{K}$, Fava GA. Benzodiazepines as a monotherapy in depressive disorders: a systematic review. Psychother Psychosom. 2018;87(2):6574.

37 Fava GA. Well-being therapy: Treatment manual and clinical applications. Basel: Karger; 2016. https://doi.org/10.1159/isbn.978-3318-05822-2.

38 Fava GA, Cosci F, Guidi J, Tomba E. Wellbeing therapy in depression: new insights into the role of psychological well-being in the clinical process. Depress Anxiety. 2017 Sep;34(9):801-8.

39 Cosci F. Well-being therapy in a patient with panic disorder who failed to respond to paroxetine and cognitive behavior therapy. Psychother Psychosom. 2015;84(5):318-9.

40 Fava GA, Rafanelli C. Iatrogenic factors in psychopathology. Psychother Psychosom. 2019;88(3):129-40

41 Fava GA, Savron G, Zielezny M, Grandi S, Rafanelli C, Conti S. Overcoming resistance to exposure in panic disorder with agoraphobia. Acta Psychiatr Scand. 1997 Apr;95(4):30612.

42 Fux M, Taub M, Zohar J. Emergence of depressive symptoms during treatment for panic disorder with specific 5-hydroxytryptophan reuptake inhibitors. Acta Psychiatr Scand. 1993 Oct;88(4):235-7.

43 Fava GA, Cosci F, Guidi J, Rafanelli C. The deceptive manifestations of treatment resistance in depression: a new look at the problem. Psychother Psychosom. 2020;89(5):26573.

44 Noyes R Jr, Garvey MJ, Cook BL. Follow-up study of patients with panic disorder and agoraphobia with panic attacks treated with tricyclic antidepressants. J Affect Disord. 1989 Mar-Jun;16(2-3):249-57.

45 Brown TA, Barlow DH. Long-term outcome in cognitive-behavioral treatment of panic disorder: clinical predictors and alternative strategies for assessment. J Consult Clin Psychol. 1995 Oct;63(5):754-65.

46 Fava GA, Rafanelli C, Grandi S, Conti S, Ruini C, Mangelli L, et al. Long-term outcome of panic disorder with agoraphobia treated by exposure. Psychol Med. 2001 Jul;31(5):891-8.

47 Otto MW, Pollack MH, Sabatino SA. Maintenance of remission following cognitive behavior therapy for panic disorder: possible deleterious effects of concurrent medication treatment. Behav Ther. 1996;27(3):473-82.

48 Fava GA. May antidepressant drugs worsen the conditions they are supposed to treat? The clinical foundations of the oppositional model of tolerance. Ther Adv Psychopharmacol. 2020 Nov;10:2045125320970325.
49 Fava GA, Belaise C. Discontinuing antidepressant drugs: lesson from a failed trial and extensive clinical experience. Psychother Psychosom. 2018;87(5):257-67.

50 Fava M, Rush AJ, Alpert JE, Balasubramani GK, Wisniewski SR, Carmin CN, et al. Difference in treatment outcome in outpatients with anxious versus nonanxious depression: a STAR*D report. Am J Psychiatry. 2008 Mar;165(3):342-51.

51 Regier DA, Rae DS, Narrow WE, Kaelber CT, Schatzberg AF. Prevalence of anxiety disorders and their comorbidity with mood and addictive disorders. Br J Psychiatry Suppl. 1998;34(34):24-8.

52 Wiethoff K, Bauer M, Baghai TC, Möller HJ, Fisher R, Hollinde D, et al. Prevalence and treatment outcome in anxious versus nonanxious depression: results from the German Algorithm Project. J Clin Psychiatry. 2010 Aug;71(8):1047-54.

53 Cameron RP, Schatzberg AF. Mixed anxietydepressive disorder. In: Stein DJ, Hollander E, editors. The American Psychiatric Publishing Textbook of Anxiety Disorders. Arlington: American Psychiatric Publishing; 2002. pp. 159-70.

54 Rickels K, Hesbacher P, Downing RW. Differential drug effects in neurotic depression. Dis Nerv Syst. 1970 Jul;31(7):468-75.

55 Fava GA, Cosci F, Sonino N. Current psychosomatic practice. Psychother Psychosom. 2017;86(1):13-30.

56 Judd LL, Paulus MJ, Schettler PJ, Akiskal HS, Endicott J, Leon AC, et al. Does incomplete recovery from first lifetime major depressive episode herald a chronic course of illness? Am J Psychiatry. 2000 Sep;157(9):1501-4.

57 Mojtabai R. Residual symptoms and impairment in major depression in the community. Am J Psychiatry. 2001 Oct;158(10):1645-51.

58 Keller MB, Boland RJ. Implications of failing to achieve successful long-term maintenance treatment of recurrent unipolar major depression. Biol Psychiatry. 1998 Sep;44(5):34860.

59 Mueller TI, Leon AC, Keller MB, Solomon DA, Endicott J, Coryell W, et al. Recurrence after recovery from major depressive disorder during 15 years of observational follow-up. Am J Psychiatry. 1999 Jul;156(7):1000-6.

60 Cosci F, Guidi J, Mansueto G, Fava GA. Psychotherapy in recurrent depression: efficacy, pitfalls, and recommendations. Expert Rev Neurother. 2020 Nov;20(11):1169-75.

61 Fava GA, Tomba E. New modalities of assessment and treatment planning in depression: the sequential approach. CNS Drugs. 2010 Jun;24(6):453-65.

62 Robinson S, Kissane DW, Brooker J, Burney S. A systematic review of the demoralization syndrome in individuals with progressive disease and cancer: a decade of research. J Pain Symptom Manage. 2015 Mar;49(3):595-610. 
63 Vehling S, Kissane DW, Lo C, Glaesmer H, Hartung TJ, Rodin G, et al. The association of demoralization with mental disorders and suicidal ideation in patients with cancer. Cancer. 2017 Sep;123(17):3394-401.

64 Fava GA, Porcelli P, Rafanelli C, Mangelli L, Grandi S. The spectrum of anxiety disorders in the medically ill. J Clin Psychiatry. 2010 Jul;71(7):910-4.

65 Griffith JL. Hope Modules: brief Psychotherapeutic Interventions to counter demoralization from daily stressors of chronic illness. Acad Psychiatry.2018 Feb;42(1):13545.

66 Tomba E, Tecuta L, Guidi J, Grandi S, Rafanelli C. Demoralization and response to psychotherapy: a pilot study comparing the sequential combination of Cognitive-Behavioral Therapy and Well-Being Therapy with clinical management in cyclothymic disorder. Psychother Psychosom. 2016;85(1):56-7.

67 Rafanelli C, Gostoli S, Buzzichelli S, Guidi J, Sirri L, Gallo P, et al. Sequential Combination of Cognitive-Behavioral Treatment and Well-Being Therapy in Depressed Patients with Acute Coronary Syndromes: A Randomized Controlled Trial (TREATED-ACS Study). Psychother Psychosom. 2020;89(6): 345-56.

68 Saha S, Lim CC, Cannon DL, Burton L, Bremner $\mathrm{M}$, Cosgrove $\mathrm{P}$, et al. Co-morbidity between mood and anxiety disorders: A systematic review and meta-analysis. Depress Anxiety. 2021 Mar;38(3):286-306.
69 Concato J, Horwitz RI. Limited Usefulness of Meta-Analysis for Informing Patient Care. Psychother Psychosom. 2019;88(5):257-62.

70 Thombs B, Turner KA, Shrier I. Defining and Evaluating Overdiagnosis in Mental Health: A Meta-Research Review. Psychother Psychosom. 2019;88(4):193-202.

71 Dubovsky SL, Ghosh BM, Serotte JC, Cranwell V. Psychotic Depression: Diagnosis, Differential Diagnosis, and Treatment. Psychother Psychosom. 2021;90(3):160-77.

72 Cohen BM, Öngür D, Babb SM. Alternative diagnostic models of the psychotic disorders - evidence based choices. Psychother Psychosom. Forthcoming.

73 Biondi M, Pasquini M, Picardi A, editors. Dimensional psychopathology. Cham: Springer; 2018. 